\title{
Cuticular Wax Variants in a Population of Switchgrass (Panicum virgatum L.)
}

Joshua M. Weaver ${ }^{\mathrm{a}, *}$, Greg Lohrey ${ }^{\mathrm{c}}$, Pernell Tomasi ${ }^{\mathrm{c}}$, John M. Dyer ${ }^{\mathrm{c}}$, Matthew A. Jenks ${ }^{\mathrm{b}}$, and Kenneth A. Feldmann ${ }^{\mathrm{a}}$

\author{
${ }^{a}$ School of Plant Sciences, University of Arizona, Tucson, AZ 85721, USA \\ ${ }^{\mathrm{b}}$ Division of Plant and Soil Sciences, West Virginia University, Morgantown, WV 26506, USA \\ ${ }^{\mathrm{c}}$ US Arid-Land Agricultural Research Center, Maricopa, AZ 85138, USA
}

\footnotetext{
* Corresponding author

Joshua M. Weaver

School of Plant Sciences

University of Arizona

303 Forbes Building

P.O. Box 210036

Tucson, AZ 85721-0036

Phone: 520-621-7158 Fax: 520-621-7168

E-Mail: jweaver2011@email.arizona.edu
} 
Keywords

Panicum virgatum; Poaceae; switchgrass; leaf; cuticular wax variants; $\beta$-diketones 


\begin{abstract}
Leaf cuticular waxes are known to influence both biotic and abiotic stress tolerances of plants. The objective of this work was to characterize the wax phenotypic diversity present in a population of 1849 switchgrass plants. We identified 92 visually distinct variant plants that possessed altered leaf glaucousness relative to the common standard type (ST), which exhibited a bluish-white (glaucous) leaf color. The variants could be grouped into three classes: 1) non-glaucous types (NG) that possessed a shiny green leaf surface, 2) reduced glaucous types (RG) that appeared less glaucous than ST, and 3) highly glaucous types (HG) that exhibited more intense bluish-white color than ST. Analyses of total cuticular wax content averaged over each of three NG (mean $304.79 \pm 15.16 \mu \mathrm{g} / \mathrm{dm}^{2}$ ), RG (mean $533.33 \pm$ $21.62 \mu \mathrm{g} / \mathrm{dm}^{2}$ ) and HG types (mean $\left.1228.23 \pm 45.74 \mu \mathrm{g} / \mathrm{dm}^{2}\right)$ showed significant differences $(\mathrm{P}<0.001)$ from three selected STs (mean $810.92 \pm 30.57 \mu \mathrm{g} / \mathrm{dm}^{2}$ ). Analysis of wax composition among these selected types revealed that the $\mathrm{C}_{33} \beta$-diketones were the most abundant wax compounds in all but NG types. Field emission scanning electron microscopy showed that abaxial leaf surfaces exhibited predominantly rod-shaped crystals, and adaxial surfaces exhibited predominantly plate-shaped wax crystals on all lines, except for NG that lacked wax crystals on the abaxial leaf surface. As a target for crop improvement, this study reveals that a large amount of variation for cuticle waxes exists within this switchgrass germplasm.
\end{abstract}




\section{Introduction}

The plant cuticle is a hydrophobic barrier that coats most aerial plant surfaces, and is composed of aliphatic compounds deposited both within and above the structural cutin matrix of the cuticle membrane (Kosma and Jenks, 2007). The cuticle plays a role in limiting plant transpiration and improving plant water conservation, which is especially important during climatological drought (Riederer and Schreiber, 2001). It also helps to protect the plant from insect herbivory, fungal pathogens and reduces potential heat stress by increasing reflection of solar radiation (Reicosky and Hanover, 1978; Jenks et al., 1995). The cuticular waxes on most plants are dominated by very long chain fatty acids (VLCFAs; $\sim \mathrm{C}_{20}$ to $\mathrm{C}_{36}$ ) and their derivatives including aldehydes, primary alcohols, alkanes, and the longer-chain length wax esters that can reach roughly 70 carbons long (Buschhaus et al., 2007). Other common wax classes include secondary alcohols, ketones and, in some species, $\beta$-diketones (von Wettstein-Knowles, 1972; Kunst and Samuels, 2003). When visualized by scanning electron microscopy, the epicuticular waxes are deposited as smooth coatings, or crystallize into a diverse array of amorphous, rodlike, or dendritic structures, depending on species and organ surface (Jeffree, 2007).

Tulloch and Hoffman (1980) identified the primary leaf surface wax components of switchgrass (Panicum virgatum L.) as $\mathrm{C}_{33} \beta$-diketone (tritiacontane-12,14-dione) and a $\mathrm{C}_{33}$ hydroxy- $\beta$-diketone (5-hydroxytritriacontane-12,14-dione), accounting for $69 \%$ and $6 \%$ of the total wax load, respectively. $\beta$-diketones have been identified in the wax of several members of the Poaceae including wheat (Triticum aestivum L.) and barley (Hordeum vulgare L.) (HenAvivi et al., 2016), and other non-Poaceae such as Rhododendron (Evans et al., 1975), and Hosta (Jenks et al., 2002). The current understanding of the impact that $\beta$-diketones have on glaucousness is previously described (Jeffree, 2007, Zhang et al. 2015, Hen-Avivi et al., 2016). 
The glaucous trait, created by a visible deposition of epicuticular wax crystals, has been a target for research in several crop species (Zhang et al., 2015). Casler et al. (2012) described the waxy bloom as a blue-colored (glaucous) coating on the stems and leaves of lowland ecotypes of switchgrass. In wheat, a similar bluish-gray leaf coating was linked to the presence of $\beta$ diketones and increased grain yields. Work to elucidate genetic control over the synthesis of $\beta$ diketones in wheat and barley revealed the involvement of the Cer-cqu gene cluster, which contains three independent genes in the $\beta$-diketone synthase polyketide pathway (Schneider et al., 2016). In barley, $\beta$-diketones are dramatically reduced in cer-c and $c e r-q$ mutants, but in $c e r$ $u$ a compensatory increase in $\beta$-diketones was observed in the absence of hydroxy- $\beta$-diketones (von Wettstein-Knowles, 1972). Switchgrass is a model herbaceous species for bioenergy production, and significant emphasis is now being placed on elucidating agronomically important traits and the underlying genes that determine biomass yield, including stress tolerance (Wright and Turhollow, 2010; Lowry et al, 2015). Characterization of existing variability in leaf wax structure and composition in switchgrass germplasm is an important first step toward understanding the underlying potential for this trait in future crop improvement strategies. In this report, a survey of the ultrastructure and chemical composition of leaf surface waxes existing on standard and glaucousness variants of the lowland ecotype (Alamo) switchgrass is presented.

\section{Material and Methods}

\subsection{Plant Material and Growth Conditions}

Seeds of lowland P. virgatum cv. Alamo were kindly provided by Dr. David Bransby, formerly of Auburn University. Seeds were treated with 80 mM EMS (ethyl methanesulfonate, Sigma-Aldrich, LLC, St. Louis MO) for four hours and rinsed several times. The initial interest in creating an EMS population was to screen, via bagging, for dominant mutations leading to self-fertility and apomixis. The EMS concentration and time for treatment were chosen from a 
dose response curve that was conducted. As no dominant mutants were observed, and there was no possibility of identifying recessive mutants in an obligate outcrossing population, the EMS treatment is not considered further in the report. After treatment, approximately 1,000 seeds were planted in each of eight flats that were stratified for three days at $4^{\circ} \mathrm{C}$ then transferred to a greenhouse. After three weeks, seedlings were transplanted into Ray Leach "cone-tainers" (SC10 Super- White Low Density, Hummert International, Springfield MO). Before transplanting to the field, plants were trimmed to a height of $30 \mathrm{~cm}$ and hardened off by exposure to ambient temperature and humidity inside a screened headhouse. In March of 2011, plants were transferred to the field in an equally spaced $(61 \mathrm{~cm}$ between plants and $91 \mathrm{~cm}$ between rows $)$ grid containing 29 rows with between 47 to 81 plants per row. Field experiments were conducted at the University of Arizona's West Campus Agricultural Center (CAC) (32 $13^{\circ} 48^{\prime \prime} \mathrm{N}, 110^{\circ}$ 57'11” W; elevation $776 \mathrm{~m})$. The West CAC field has a Vinton Soil Series (0-3\% slope, fine sandy loam, Typic Torrifluvents) with irrigation water that is slightly alkaline and high in calcium (Weaver et al., 2014). This semi-arid climate (low relative humidity $\mathrm{RH}<20 \%$ ) has a bimodal annual precipitation that is concentrated during the summer monsoon months, July through September, and during the winter storm months of December through January. In 2011, Tucson observed an average yearly temperature of $69.9^{\circ} \mathrm{F}$ and annual precipitation of $31.06 \mathrm{~cm}$, which was similar to the previous 30 -year averages of $69.4^{\circ} \mathrm{F}$ and $29.34 \mathrm{~cm}$, respectively (NOAA, 2014). In September 2011, variants were scored for plant height, stature, number of tillers, leaf width and curling and plant color/reflectance. Among the 1849 transplants, most of the plants displayed a moderate amount of leaf glaucousness and are referred to as standard type (ST). 92 plants exhibited distinct visible differences in surface glaucousness when compared to the ST. The 92 variants were grouped into three distinct categories including three non-glaucous 
(NG), 14 reduced glaucous (RG), and 75 highly glaucous (HG) types. In addition, six plants were identified with extreme glaucousness on both leaf surfaces along with a very short stature and few tillers. These six plants were not considered further. From these primary visual screens, we selected three representatives from the ST, NG, RG, and HG types for a more detailed analysis of the glaucousness trait. For five successive growing seasons these individuals expressed their respective glaucous phenotypes. None of the glaucous variants, or any of the other phenotypes that were identified, was chimeric as would be expected if the mutagenesis treatment contributed to any of the observed phenotypes in the M1 population. As such, the variation observed is due to natural variation in the population.

\subsection{Leaf Cuticle Wax Extraction}

To best represent a typical wax chemical composition for the ST and each type of variant, leaf samples were collected during the first year anthesis or the R4 stage of reproductive-floral development (Moore et al., 1991). From tillers having fully expanded second leaves below the flag leaf, leaf samples were collected in each of the three selected plants within a class. Leaf samples were excised and placed individually in pollination bags (No. 404, Lawson, Northfield IL) for transport to the lab and wax extraction (in less than 1 hour). Mean wax amounts are presented in this report as the average of three selected plants representative of the ST and each of the variant types. In mid-leaf sections $(22.5 \times 1.3 \mathrm{~cm}(\mathrm{~L} \mathrm{x} \mathrm{W}))$ including the mid-vein, leaf area was determined using a flatbed scanner and image analysis software (LIA32ver.0.377e, Nagoya University, Nagoya, Japan). Leaf sections were cut into three segments, to fit inside 20 ml scintillation vials (Teflon-lined caps, VWR International, LLC, Brisbane CA), and submerged in $15 \mathrm{ml}$ of hexane ( $99 \%$ GC hexane, Sigma-Aldrich LLC, St. Louis, MO) for 45 seconds before the wax extracts were dispensed into clean scintillation vials, as described by Jenks et al. (1995). The leaf segments were briefly $(2 \mathrm{sec})$ rinsed once more with new hexane $(5 \mathrm{ml})$ and hexane 
fractions combined for each leaf sample. The samples appeared clear with a slight yellow tint (absent in green coloration typical of chlorophylls) before being evaporated to dryness.

\subsection{Chemical analyses of waxes}

Gas chromatography (GC) with flame ionization detection was performed using an Agilent 7890A GC-FID. The internal standard hexadecane $(5 \mu \mathrm{g})$ was added to evaporated samples and waxes were derivatized by heating in (75 $\mu$ l) N,O-bis(trimethylsilyl) trifluoroacetamide (BSTFA, Sigma-Aldrich LLC, St. Louis, MO) at $100^{\circ} \mathrm{C}$ for $15 \mathrm{~min}$. The BSTFA was evaporated under nitrogen and the samples were suspended in hexane $(25 \mu \mathrm{l})$ for analyses. Compounds were injected in the GC and then separated using a $12 \mathrm{~m}, 0.2 \mu \mathrm{m}$ HP-1 capillary column with helium as the carrier gas. The $\mathrm{GC}$ was programmed with an initial temperature of $80^{\circ} \mathrm{C}$ and increased at $15^{\circ} \mathrm{C} / \mathrm{min}$. to $260^{\circ} \mathrm{C}$ where the temperature was held for $10 \mathrm{~min}$., then increased at $5^{\circ} \mathrm{C} / \mathrm{min}$. to $320^{\circ} \mathrm{C}$, where the temperature was held for $24 \mathrm{~min}$. for a total run time of $58 \mathrm{~min}$. The composition of waxes were analyzed by a GC-Mass Spectrometer (MS) using an Agilent 7890A GC and 5975C Triple-Axis detector MS with $12 \mathrm{~m}, 0.2 \mu \mathrm{m}$ HP-Ultra 1 capillary column with helium gas as a carrier, using a similar temperature profile as used for GC-FID. The molecular identities of individual wax compounds were determined by quadrupole electron impact GC-MS, using relative retention time and mass fragment spectra of each molecular species, in addition to comparisons to NIST MS Search 2.0 database and bona fide standards run on the same instrument. However, those missing from the library were compared to previously published spectra or elucidated from their ion fragmentation patterns (Tulloch and Hoffman, 1980; Wen and Jetter, 2009).

Quantification was based on FID peak areas, using Enhanced data analysis G1701EA software (Agilent Technologies, Santa Clara, CA), relative to the internal standard. Specific correction factors were developed from external standards and applied to the peak areas of the 
free fatty acids $\left(\mathrm{C}_{20}, \mathrm{C}_{21}, \mathrm{C}_{24}, \mathrm{C}_{26}\right.$, and $\left.\mathrm{C}_{28}\right)$, primary alcohols $\left(\mathrm{C}_{20}, \mathrm{C}_{22}, \mathrm{C}_{24}, \mathrm{C}_{25}, \mathrm{C}_{26}, \mathrm{C}_{28}, \mathrm{C}_{29}\right.$, and $\left.\mathrm{C}_{30}\right)$ and alkanes $\left(\mathrm{C}_{23}, \mathrm{C}_{24}, \mathrm{C}_{25}, \mathrm{C}_{26}, \mathrm{C}_{27}, \mathrm{C}_{28}, \mathrm{C}_{29}, \mathrm{C}_{30}, \mathrm{C}_{31}, \mathrm{C}_{32}\right.$ and $\left.\mathrm{C}_{33}\right)$. For all other peaks, a correction factor of 1 was assigned. A representative chromatogram of the 53 wax compounds identified and characterized using GC-MS, which included acids, aldehydes, 1- alcohols, alkanes, $\beta$-diketones and esters, is shown in Supplemental Fig. 1. Further experiments are needed for definitive structural identification of five putative compounds: $\mathrm{C}_{19}$ acid, $\mathrm{C}_{20}$ acid, $\mathrm{C}_{21}$ acid, $\mathrm{C}_{33}$ ketol and $\mathrm{C}_{33} \mathrm{OH}$ ketol. Additionally, three tentatively identified compounds, $\mathrm{C}_{31}$ acid, $\mathrm{C}_{32}$ alcohol and $\mathrm{C}_{33} \beta$-diketone (tritriacontane-14,16-dione), were found to be co-eluting with $\mathrm{C}_{33} \beta$ diketone (Supplemental Fig. 1B). Since these molecular identities were not confirmed, they were summed in the total unknowns and not discussed further. Total wax amounts (summed across all quantified compounds) were averaged across the three selected individuals of each phenotypic class and expressed as a function of leaf surface area $\left(\mu \mathrm{g} / \mathrm{dm}^{2}\right)$ (Table 1). Wax composition was analyzed using JMP software, version 12 (SAS Inc. Cary, NC), to calculate the Pearson productmoment correlation coefficient and for means comparisons by Student's $t$-test. The statistical significance was assessed at the $5 \%$ probability level unless otherwise indicated.

\subsection{Scanning electron microscopy}

Ultrastructural characterization of abaxial (facing away from the stem) and adaxial (facing the stem) leaf surface waxes was performed on three leaves of a representative plant of the standard type (ST) and a representative plant for each of the three variant types (NG, RG, and HG). Leaf samples were air-dried ca. 32 hours and then small pieces mounted on pin stubs using double-sided carbon tape. Leaf samples were sputter coated twice at $0^{\circ}$ and $40^{\circ}$ with ca. $7 \mathrm{~nm}$ total of platinum (Hummer 6.1 sputtering Device, Anatech USA, Union City, USA). Micrographs were produced using a field emission scanning electron microscope (4800 FESEM; Hitachi, Tokyo, Japan). 


\section{Results}

Of the 1849 plants screened for visible glaucousness, 1751 plants had a bluish-white color and moderate amounts of visible glaucousness on both the abaxial and adaxial leaf surfaces. This phenotype is referred to as the standard type (ST) for Alamo. 92 plants were identified as having overall normal growth architecture and a leaf surface reflectance that differed dramatically from ST and these variants were classified into three unique types (Fig. 1A-D). The three nonglaucous types (NG) were characterized by a shiny green abaxial leaf surface and an adaxial surface that retained the glaucous (bluish-white) trait (Fig. 1B). The 14 reduced glaucous types (RG) were distinguished by having a visual glaucousness intermediate to NG and ST, i.e. reduced blue coloration, on the abaxial surface only (Fig. 1C). Although not performed in the current study of switchgrass waxes, Jetter and Schaffer (2001) describe the use of adhesive gum arabic for the extraction of one side of the leaf surface in P. laurocerasus leaves, a technique that could provide a means to extracting abaxial and adaxial waxes separately for the future detailed analysis of this trait in switchgrass. Seventy-five highly glaucous types (HG) had visible glaucousness greater than observed on ST and this occurred on both abaxial and adaxial leaf surfaces (Fig. 1D).

Analysis of leaf wax content and composition using GC/FID/MS confirmed the presence of prominent isomers $\mathrm{C}_{33} \beta$-diketone (tritiacontane-12,14-dione) and $\mathrm{C}_{33}$ hydroxyl- $\beta$-diketone (5hydroxytritriacontane-12,14-dione), which were supported by mass spectra that contained diagnostic ions at m/z 100, 183, 122 and m/z 159, respectively (Supplemental Figs. 2 and 3). Mean total wax amounts were determined for each of three ST (mean $810.92 \pm 30.57 \mu \mathrm{g} / \mathrm{dm}^{2}$ ), NG (mean $\left.304.79 \pm 15.16 \mu \mathrm{g} / \mathrm{dm}^{2}\right), \mathrm{RG}\left(\right.$ mean $533.33 \pm 21.62 \mu \mathrm{g} / \mathrm{dm}^{2}$ ) and HG (mean $1228.23 \pm$ $45.74 \mu \mathrm{g} / \mathrm{dm}^{2}$ ) types as representatives of all of the plants in each class (Table 1). The relatively 
small standard errors indicate that the visible glaucousness trait for these selections is closely associated with total wax loads.

Comparisons of chemical classes revealed that NG types were similar to STs in amounts of 1-alcohols, but significantly lower $(\mathrm{P}<0.01)$ than STs in the mean amounts of acids, aldehydes, alkanes, $\beta$-diketones, esters and unknowns. The RG types were significantly lower $(\mathrm{P}<0.01)$ than STs in all chemical classes except for the $\beta$-diketones, which were similar to ST's. The HG types were similar to STs in the amounts of acids, aldehydes, alkanes, and unknowns. The HG types had significantly lower $(\mathrm{P}<0.01)$ amounts of 1 -alcohols and esters than STs, but were significantly higher $(\mathrm{P}<0.001)$ in amounts of $\beta$-diketones. In terms of the percentage of total wax (calculated from Table 1), $\beta$-diketones in the HG (46.14\%) and RG (22.88\%) types were higher than the STs (18.25\%) and NG type (1.69\%).

Comparisons between wax profiles showed differences in the carbon length distributions of several chemical classes that are worth noting (Fig. 2). For fatty acids, the $\mathrm{C}_{32}$ acids were the highest in STs $\left(81.11 \pm 9.53 \mu \mathrm{g} / \mathrm{dm}^{2}\right)$ and $\mathrm{HG}\left(75.31 \pm 4.68 \mu \mathrm{g} / \mathrm{dm}^{2}\right)$ types, but were not significantly different from each other. The $\mathrm{C}_{32}$ acids in $\mathrm{RG}\left(55.12 \pm 4.11 \mu \mathrm{g} / \mathrm{dm}^{2}\right)$ and $\mathrm{NG}$ types $\left(6.90 \pm 0.78 \mu \mathrm{g} / \mathrm{dm}^{2}\right)$ were significantly lower $(P<0.05)$ than in the other types, with the $C_{30}$ acids in NG types (12.01 \pm 1.18$)$ being the most abundant (Fig. 2 B).

The $\mathrm{C}_{33} \beta$-diketones were the most abundant compounds on the leaf surface of ST, RG and HG types, whereas $\beta$-diketones were extremely low in NG types (Fig. 2). The $\mathrm{C}_{33} \beta$-diketones of NG $\left(5.17 \pm 1.12 \mu \mathrm{g} / \mathrm{dm}^{2}\right)$ were significantly lower $(\mathrm{P}<0.001)$ than STs $\left(144.48 \pm 21.10 \mu \mathrm{g} / \mathrm{dm}^{2}\right)$, while HG $\left(553.79 \pm 25.58 \mu \mathrm{g} / \mathrm{dm}^{2}\right)$ types were significantly higher $(\mathrm{P}<0.001)$ than STs (Fig. 3). The mean amounts of $\mathrm{C}_{33} \beta$-diketones for RG $\left(119.30 \pm 11.57 \mu \mathrm{g} / \mathrm{dm}^{2}\right)$ were similar to STs. 
FE-SEM imaging revealed that the adaxial leaf surfaces of all types (ST, NG, RG and HG) exhibited plate-shaped structures (Fig. 4A-D) whereas the abaxial surfaces of all types except NG exhibited rod-shaped wax crystals (Fig. 4 E, G, H). The NG abaxial surfaces completely lacked wax crystals and displayed a flattened and smoothed-over waxy surface (Fig. 4F).

\section{Discussion}

We report here for the first time an ultrastructural analysis of epicuticular waxes on ST lowland Panicum virgatum, revealing the presence of densely distributed diverse plate- and rodshaped epicuticular wax crystals over the switchgrass leaf surface. We also report that the cuticular wax constituents of the ST switchgrass cultivar Alamo were comparable to those previously reported in upland P. virgatum cv. Nebraska 28 (Tulloch and Hoffman, 1980). Besides presenting this more detailed analysis of waxes on ST switchgrass, we report a comprehensive analysis of the wax ultrastructure and chemical composition on three newly defined types of switchgrass: non-glaucous (NG), reduced glaucous (RG), and highly glaucous (HG). These variant types were identified based on the level of visible glaucousness. Three representatives of each type were sampled and an average wax ultrastructural and chemical compositional profile across each type was determined as a way to describe the representative wax profiles. The waxes present on the three individuals within each type were similar, as evidenced (in part) by the very low standard errors we report for the average wax amounts determined using GC-MS. Whether the variants within a type might arise by mutations in the same wax-associated gene, or different genes, is uncertain. Moreover, allelism tests within these phenotypic groups are still needed to ascertain whether the selected individuals represent the same or different complementation (allelic) groups. The results presented here clearly demonstrate the potential genetic diversity for the glaucousness trait present in the switchgrass germplasm, as well as providing a useful 
description of the microstructural and chemical profiles of the surface waxes on ST and new variant types for glaucousness.

The NG and HG types produced significantly lower and higher amounts of $\mathrm{C}_{33} \beta$-diketones in comparison to STs, respectively. NG types also lacked the abaxial wax structures that were present in RG, HG and ST types, which is consistent with NG's glossy leaf phenotype. Alcohols were found to be equally abundant in NG and STs, suggesting the presence of alcohols is associated with the plate-shaped wax structures on the adaxial side. In contrast to the lower amounts of $\beta$-diketones and absence of abaxial wax structures on NG, we can glean from this that the presence of rod-shaped abaxial wax structures on ST indicates the presence of $\beta$ diketones. The biochemical and morphological differences in wax content and structure suggest that the $\beta$-diketones play a role in determining the glaucous trait in switchgrass. Notably however, the RG switchgrass exhibited reduced glaucousness but little change in $\beta$-diketones, indicating that other wax compounds also affect the appearance of the switchgrass leaf glaucousness trait.

Similar to the Hordeum mutants $(C e r-c,-q$ and $-u)$ and the Triticum $w l$ locus mutants, which have reduced amounts of $\beta$-diketones or the absence of hydroxyl- $\beta$-diketone, respectively, our findings suggest that NG types similarly possess a major inhibition of the $\beta$-diketone biosynthetic pathway (Schneider et al. 2016). Relative to ST, we observed an increase in production of all wax constituents on HG types, and a general reduction in all wax constituents on RG types, but no significant reduction in total $\beta$-diketones. Whether the chemical differences observed in these types are due to modifications in metabolic, regulatory, and/or other types of gene expression awaits further studies. 
This is the first comprehensive description of glaucous variants in switchgrass. Our results show that the visible wax phenotypes (i.e. high or low glaucousness) on variants were closely correlated to the total amount of waxes as calculated using GC-MS, and thus the amount of visual glaucousness was an indicator of total wax load. Notwithstanding, visible wax amount (intensity of glaucousness) is not always associated with total wax weight, and this is best explained by the fact that glaucousness is positively correlated with the size and density of reflective surface wax crystal facets (Jenks et al., 1994; Grant et al., 2003). In some plants, waxes do not form crystals (and so do not reflect light) even though the wax load may be relatively high. Switchgrass devoid of rod-shaped wax structures, i.e. NG types, has the potential for pathogen resistance, as observed in the irg1/palml mutant in Medicago truncatula, and resistance to phytophagous insects, as observed in the bm mutants in Sorghum bicolor (Stark and Weibel, 1981; Uppalapati et al., 2012). The genetic resources described here provide valuable new tools for future studies to elucidate the eco-physiological functions of cuticular waxes, and the potential to apply genetic approaches in switchgrass to improve its biomass yield in more arid and similarly challenging environments. Further studies are needed to examine the genetic, biochemical, and eco-physiological implications for surface waxes on leaves using the three unique wax types identified by this screen.

\section{Acknowledgments}

JMW would like to acknowledge the funding supported by the Sloan Indigenous Graduate Partnership and the Mississippi Band of Choctaw Indians - Tribal Scholarship Program. We thank K. Milward, L. S. Montes-Sujo and M. J. Feldmann, for planting, collection of leaf material and wax extraction. We also thank Ed Bedrick, of the Bio-5 Institute at the University of Arizona, for statistical consultation. All SEM images and data were collected in the W.M. Keck 
Center for Nano-Scale Imaging in the Department of Chemistry and Biochemistry at the

University of Arizona with funding from the W.M. Keck Foundation Grant.

\section{Legends}

\section{Figure 1:}

Phenotypic characterization of ST and three variant types: NG, RG and HG. A-D) Photographic images of whole plants reveal abaxial leaf surfaces that vary in glaucousness from green (NG type) to whitish blue (HG type). The insets indicate changes in glaucousness based on leaf sidedness with the abaxial surfaces identified by white arrows and the adaxial identified by black arrows.

\section{Figure 2:}

Wax chemical profiles, presented as chemical classes, on the leaf segments of ST $(n=3)$, and three variant types NG $(n=3), \mathrm{RG}(n=3)$, and HG $(n=3)$. A-D) Carbon chain lengths of individual constituents are shown for each wax chemical class in $\mu \mathrm{g} / \mathrm{dm}^{2}$ (mean $\pm \mathrm{SE}$ ). Numbers beside bars indicate actual amounts where the total is above the $\mathrm{Y}$ axis scale. Esters are a sum of five identified ester compounds.

\section{Figure 3:}

Amounts of $\mathrm{C}_{33} \beta$-diketones on leaf segments of switchgrass for ST ( $\left.n=3\right)$, and three variant types NG $(n=3)$, RG $(n=3)$, and HG $(n=3)$. Data represent the average and standard error (presented in $\left.\mu \mathrm{g} / \mathrm{dm}^{2}\right)$. Significance values ( $\mathrm{t}-$ test) are indicated by the asterisks; $* * * \mathrm{P}<0.001$.

\section{Figure 4:}

Ultrastructural characterization of leaf epicuticular wax on switchgrass of ST, NG, RG and HG types. A-D) Micrographic images of the adaxial surfaces of leaves reveal plate-shaped wax crystal morphology of ST, NG, RG and HG. E-H) Rod-shaped wax crystal morphology on the abaxial surface of ST (similar to RG and HG) and absence of wax crystals on NG switchgrass.

\section{Table 1:}

Amounts of total leaf cuticular waxes, and totals for six chemical classes, on leaves in ST $(n=3)$, and three variant types NG $(n=3)$, RG $(n=3)$, and HG ( $n=3)$. Data is presented in $\mu \mathrm{g} / \mathrm{dm}^{2}$ (mean $\pm \mathrm{SE}$ ). Acid is free fatty acid; 1 alcohol is primary alcohol. Significance values (t-test) are indicated by the asterisks; $* \mathrm{P}<0.05$, $* * \mathrm{P}<0.01$, $* * * \mathrm{P}$ $<0.001$.

\section{Supplemental Figure 1:}

GC-MS chromatogram of hexane soluble cuticular wax components obtained after BSTA derivatization from the ST. A) Retention times 5.6-24 min., numbered constituents are as listed below. B) Retention times 24-42 min., symbols within the peaks at baseline indicated minor coelution compounds as listed below. ITSD: internal standard hexadecane (5 $\mu \mathrm{g}$ ). (1) $\mathrm{C}_{23}$ alkane, (2) $\mathrm{C}_{19}$ acid, (3) $\mathrm{C}_{20}$ alcohol, (4) $\mathrm{C}_{24}$ alkane, (5) $\mathrm{C}_{20}$ acid, (6) $\mathrm{C}_{25}$ alkane, (7) $\mathrm{C}_{21}$ acid, (8) $\mathrm{C}_{22}$ alcohol, (9) $\mathrm{C}_{26}$ alkane, (10) $\mathrm{C}_{24}$ aldehyde, (11) $\mathrm{C}_{22}$ acid, (12) $\mathrm{C}_{27}$ alkane, (13) $\mathrm{C}_{25}$ aldehyde, (14) $\mathrm{C}_{23}$ acid, (15) $\mathrm{C}_{24}$ alcohol, (16) $\mathrm{C}_{28}$ alkane, (17) $\mathrm{C}_{26}$ aldehyde, (18) $\mathrm{C}_{24}$ acid, (19) $\mathrm{C}_{29}$ alkane, (20) $\mathrm{C}_{27}$ aldehyde, (21) $\mathrm{C}_{25}$ acid, (22) $\mathrm{C}_{26}$ alcohol, (23) $\mathrm{C}_{30}$ alkane, (24) $\mathrm{C}_{28}$ aldehyde, (25) $\mathrm{C}_{26}$ acid, (26) $\mathrm{C}_{27}$ alcohol, (27) $\mathrm{C}_{31}$ alkane, (28) $\mathrm{C}_{29}$ aldehyde, (29) $\mathrm{C}_{27}$ acid, (30) $\mathrm{C}_{28}$ alcohol, (31) $\mathrm{C}_{25}$ alcohol, (32) $\mathrm{C}_{32}$ alkane, (33) $\mathrm{C}_{30}$ aldehyde, (34) $\mathrm{C}_{28}$ acid, (35) $\mathrm{C}_{29}$ alcohol, (36) $\mathrm{C}_{33}$ alkane, (37) $\mathrm{C}_{29}$ acid, (38) $\mathrm{C}_{30}$ alcohol, (39) $\mathrm{C}_{32}$ aldehyde, (40) $\mathrm{C}_{30}$ acid, (41) $\mathrm{C}_{31}$ alcohol, ( $\left(\mathrm{C}_{31}\right.$ acid, $\left(\mathrm{C}_{32}\right.$ alcohol, (42) $\mathrm{C}_{33} \beta$-diketone (tritriacontane-12,14-dione), ( $\Delta \mathrm{C}_{33} \beta$-diketone (tritriacontane-14,16dione), (43) $\mathrm{C}_{33}$ ketol, (44) $\mathrm{C}_{32}$ acid, (45) $\mathrm{C}_{34}$ alcohol, (46) $\mathrm{C}_{33}$ hydroxy- $\beta$-diketone (5-hydroxytritriacontane-12,14dione), (47) $\mathrm{C}_{33} \mathrm{OH}$ ketol, (48) $\mathrm{C}_{34}$ acid, (49) ester 1, (50) ester 2, (51) ester 3, (52) ester 4, (53) ester 5. 


\section{Supplemental Figure 2:}

Mass spectrum of $\mathrm{C}_{33} \beta$-diketone (tritiacontane-12,14-dione) with notable diagnostic ions at m/z 100, 183 and 122.

\section{Supplemental Figure 3:}

The mass spectrum of $\mathrm{C}_{33}$ hydroxy- $\beta$-diketone (5-hydroxytritriacontane-12,14-dione) with notable diagnostic ion $\mathrm{m} / \mathrm{z} 159$.

\section{References}

Buschhaus, C., Herz, H., Jetter, R., 2007. Chemical composition of the epicuticular and intracuticular wax layers on the adaxial side of Ligustrum vulgare leaves. New Phytol 176, 311-316.

Casler, M. D., 2012. Switchgrass breeding, genetics, and genomics. In: Monti, A. (Ed.), Switchgrass: a valuable biomass crop for energy. Springer London, London, pp. 29-53.

Evans, D., Knights, B. A., Math, V. B., Ritchie A. L., 1975. $\beta$-Diketones in Rhododendron waxes. Phytochemistry 14, 2447-2451.

Grant, R. H., Heisler, G. M., Gao, W., Jenks, M., 2003. Ultraviolet leaf reflectance of common urban trees and the prediction of reflectance from leaf surface characteristics. Agricultural and Forest Meteorology 120, 127139.

Hen-Avivi, S., Savin, O., Racovita, R. C., Lee, W.-S., Adamski, N. M., Malitsky, S., Almekias-Siegl, E., Levy, M., Vautrin, S., Bergès, H., Friedlander, G., Kartvelishvily, E., Ben-Zvi, G., Alkan, N., Uauy, C., Kanyuka, K., Jetter, R., Distelfeld, A., Aharoni, A., 2016. A metabolic gene cluster in the wheat W1 and the barley Cercqu loci determines $\beta$-diketone biosynthesis and glaucousness. The Plant Cell 28, 1440-1460.

Jeffree, C. E., 2007. The fine structure of the plant cuticle. Annual plant reviews volume 23: Biology of the plant cuticle. Blackwell Publishing Ltd, pp. 11-125.

Jenks, M. A., Gaston, C. H., Goodwin, M. S., Keith, J. A., Teusink, R. S., Wood, K. V., 2002. Seasonal variation in cuticular waxes on Hosta genotypes differing in leaf surface glaucousness. HortScience 37, 673-677

Jenks, M. A., Rich, P. J., Ashworth, E. N., 1994. Involvement of cork cells in the secretion of epicuticular wax filaments on Sorghum bicolor (L.) Moench. International Journal of Plant Sciences 155, 506-518.

Jenks, M. A., Tuttle, H. A., Eigenbrode, S. D., Feldmann, K. A., 1995. Leaf epicuticular waxes of the eceriferum mutants in Arabidopsis. Plant Physiol 108, 369-377.

Jetter, R., Schaffer, S., 2001. Chemical composition of the Prunus laurocerasus leaf surface. Dynamic changes of the epicuticular wax film during leaf development. Plant Physiol 126, 1725-1737.

Kosma, D. K., Jenks, M. A., 2007. Eco-physiological and molecular-genetic determinants of plant cuticle function in drought and salt stress tolerance. In: Jenks, M. A., Hasegawa, P. M., Jain, S. M. (Eds.), Advances in molecular breeding toward drought and salt tolerant crops. Springer Netherlands, Dordrecht, pp. 91-120.

Kunst, L., Samuels, A. L., 2003. Biosynthesis and secretion of plant cuticular wax. Prog Lipid Res. 42, 51-80.

Lowry, D. B., Taylor, S. H., Bonnette, J., Aspinwall, M. J., Asmus, A. L., Keitt, T. H., Tobias, C. M., Juenger, T. E., 2015. QTLs for biomass and developmental traits in switchgrass (Panicum virgatum). BioEnergy Research 8, 1856-1867.

Moore, K. J., Moser, L. E., Vogel, K. P., Waller, S. S., Johnson, B. E., Pedersen, J. F., 1991. Describing and quantifying growth-stages of perennial forage grasses. Agron J 83, 1073-1077.

National Oceanic and Atmospheric Administration (NOAA), 2014. Monthly and daily normal (1981-2010) plus daily extremes (1895-2014) for Tucson, AZ. http://www.wrh.noaa.gov/twc/climate/tus.php (accessed 07.05.14).

Reicosky, D. A., Hanover, J. W., 1978. Physiological effects of surface waxes: I. Light reflectance for glaucous and nonglaucous Picea pungens. Plant Physiol 62, 101-104.

Riederer, M., Schreiber, L., 2001. Protecting against water loss: analysis of the barrier properties of plant cuticles. Journal of Experimental Botany 52, 2023-2032.

Schneider, L. M., Adamski, N. M., Christensen, C. E., Stuart, D. B., Vautrin, S., Hansson, M., Uauy, C., von Wettstein-Knowles, P., 2016. The Cer-cqu gene cluster determines three key players in a $\beta$-diketone synthase polyketide pathway synthesizing aliphatics in epicuticular waxes. J Exp Bot 67, 2715-2730.

Starks, K.J., Weibel D.E. 1981. Resistance in bloomless and sparse-bloom sorghum to greenbugs. Environ Entomol 10:963-965.

Tulloch, A. P., Hoffman, L. L., 1980. Epicuticular wax of Panicum virgatum. Phytochemistry 19, 837-839. 
Uppalapati, S. R., Ishiga, Y., Doraiswamy, V., Bedair, M., Mittal, S., Chen, J., Nakashima, J., Tang, Y., Tadege, M., Ratet, P., Chen, R., Schultheiss, H., Mysore, K. S., 2012. Loss of abaxial leaf epicuticular wax in Medicago truncatula $\mathrm{irg} 1 / \mathrm{palm} 1$ mutants results in reduced spore differentiation of anthracnose and nonhost rust pathogens. The Plant Cell 24, 353-370.

von Wettstein-Knowles, P., 1972. Genetic control of $\beta$-diketone and hydroxyl- $\beta$-diketone synthesis in epicuticular waxes of barley. Planta, 106, 113-130.

Weaver, J. M., Sujo, L. S. M., Feldmann, K. A., 2014. A Simplified technique for the propagation of shoots from nodes of switchgrass (Panicum virgatum L.) genotypes. BioEnergy Research 7, 1351-1357.

Wen, M., Jetter, R., 2009. Composition of secondary alcohols, ketones, alkanediols, and ketols in Arabidopsis thaliana cuticular waxes. J Exp Bot 60, 1811-1821.

Wright, L., Turhollow, A., 2010. Switchgrass selection as a "model" bioenergy crop: A history of the process. Biomass and Bioenergy 34, 851-868.

Zhang, Z., Wei, W., Zhu, H., Challa, G. S., Bi, C., Trick, H. N., Li, W., 2015. W3 is a new wax locus that is essential for biosynthesis of $\beta$-diketone, development for glaucousness, and reduction of cuticle permeability in common wheat. PLoS One 10, e0140524. 
Tables and Figures
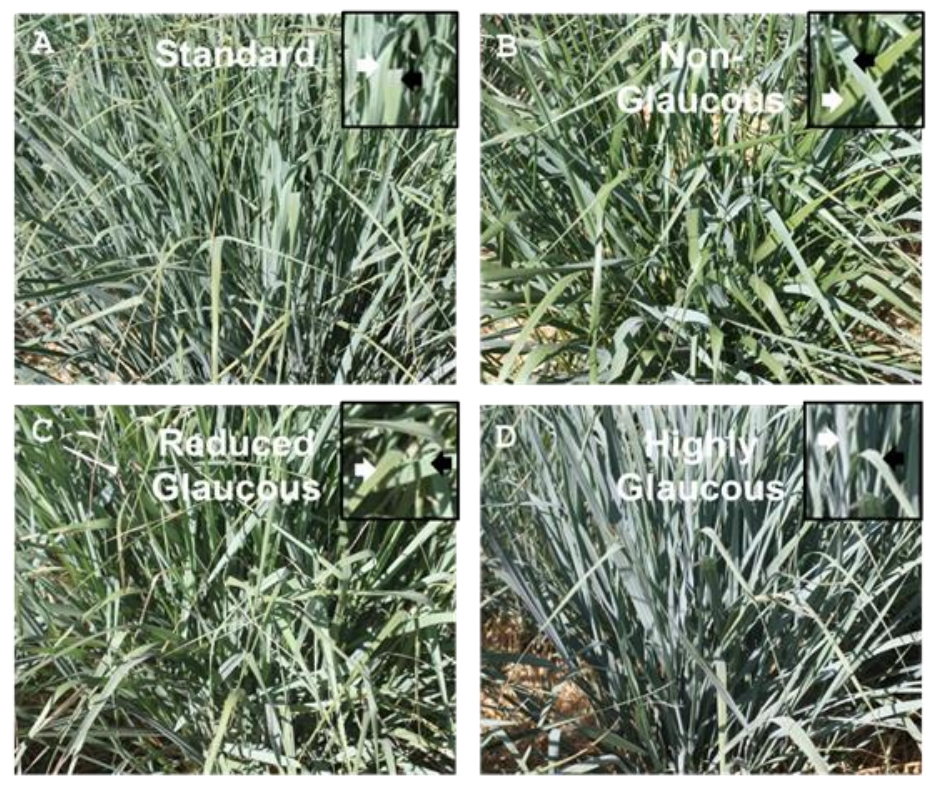

Figure 1

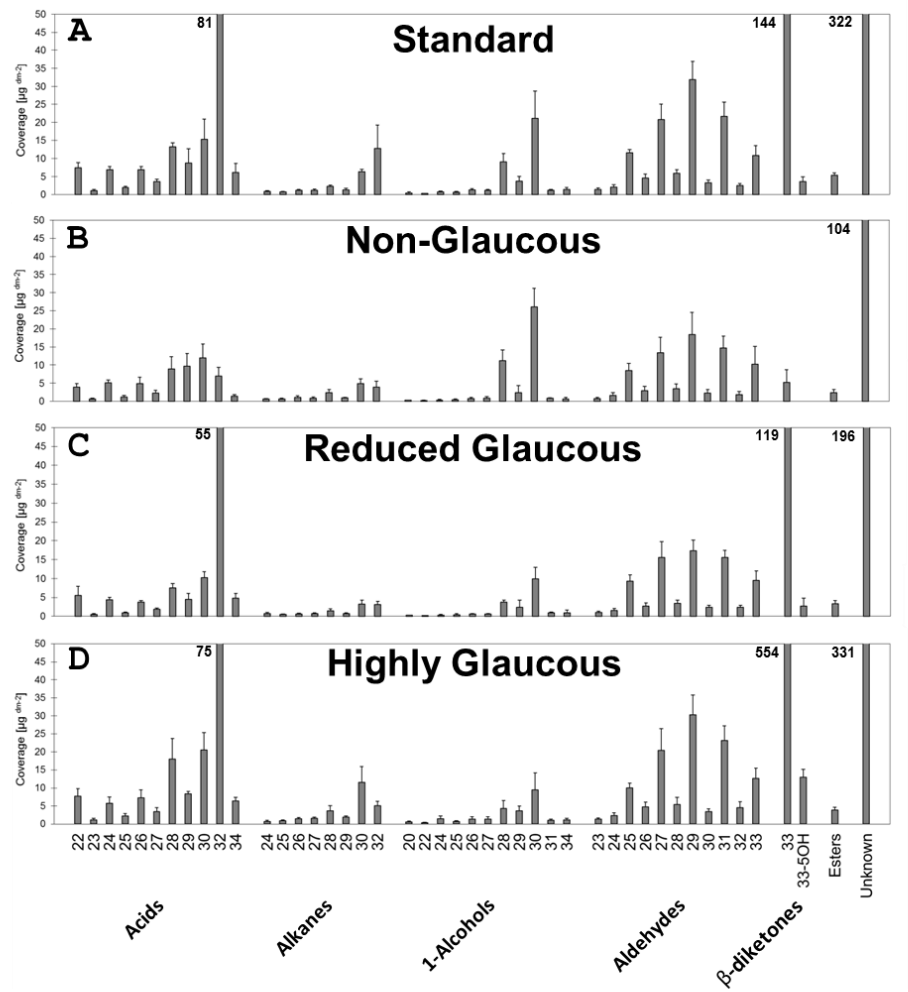

Figure 2 


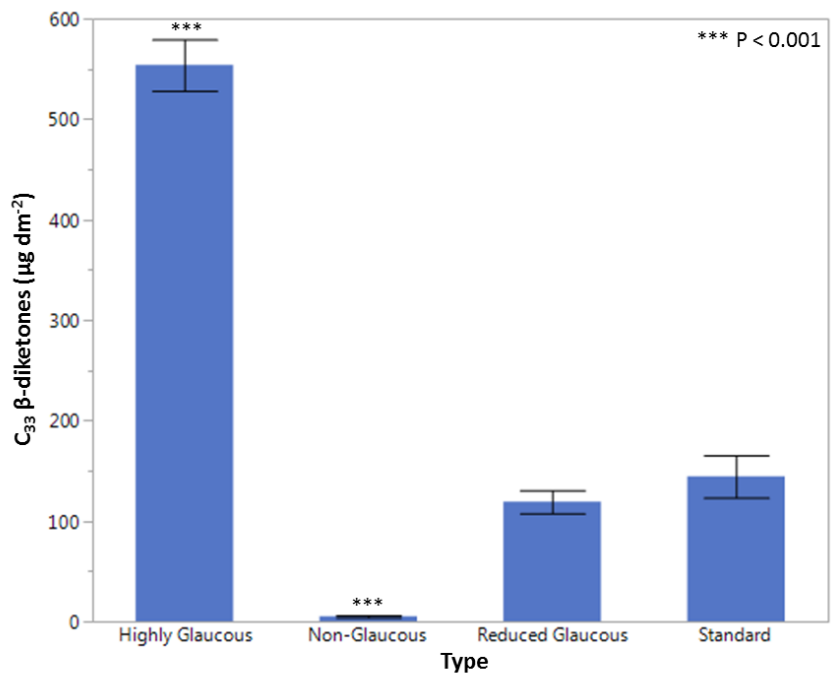

Figure 3

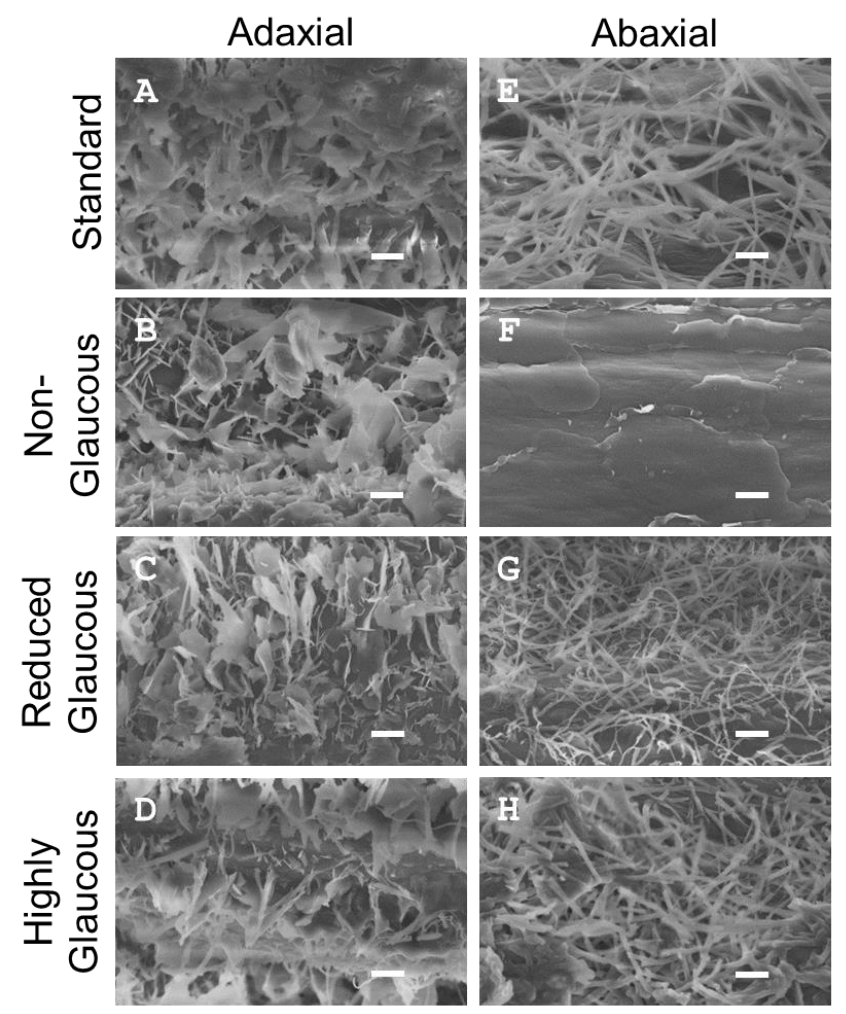

Figure 4 
Table 1

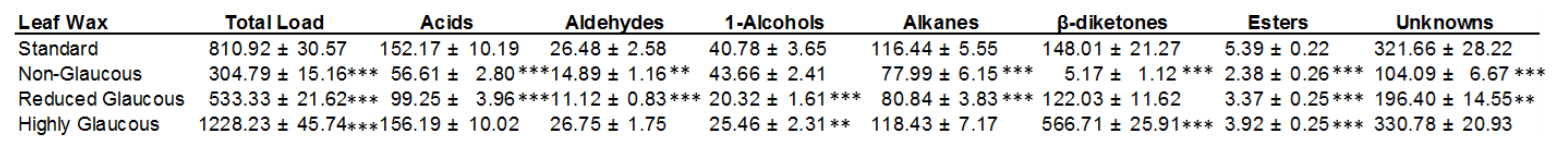

Supplemental Figures

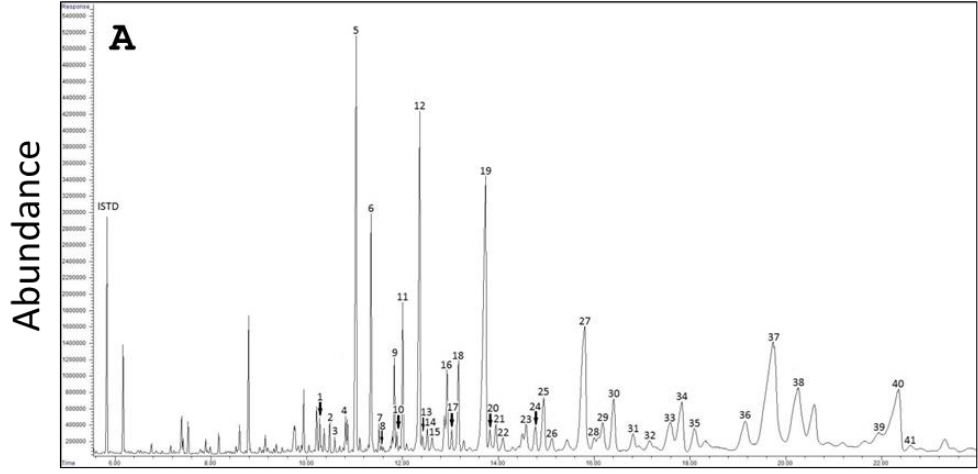

Retention Time

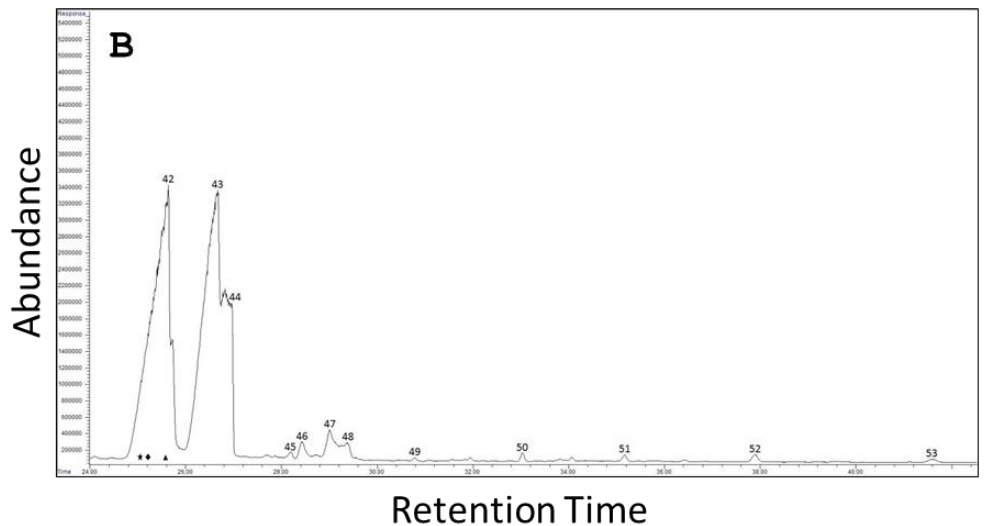

Supplemental Figure 1 


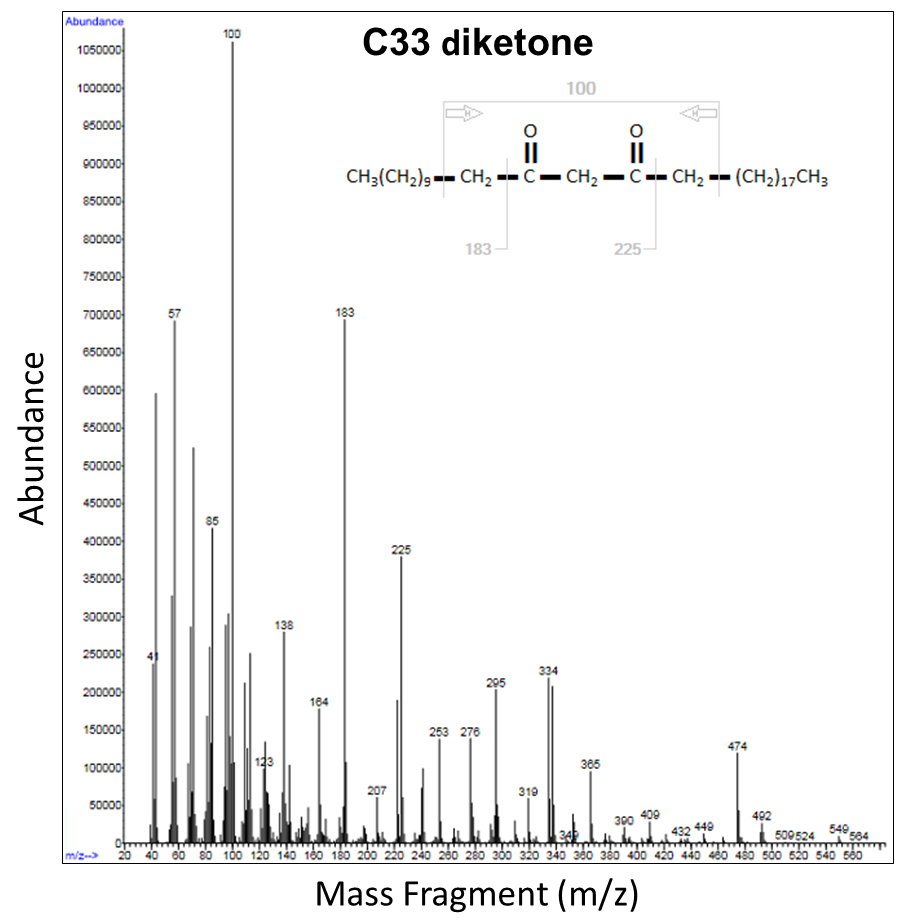

Supplemental Figure 2

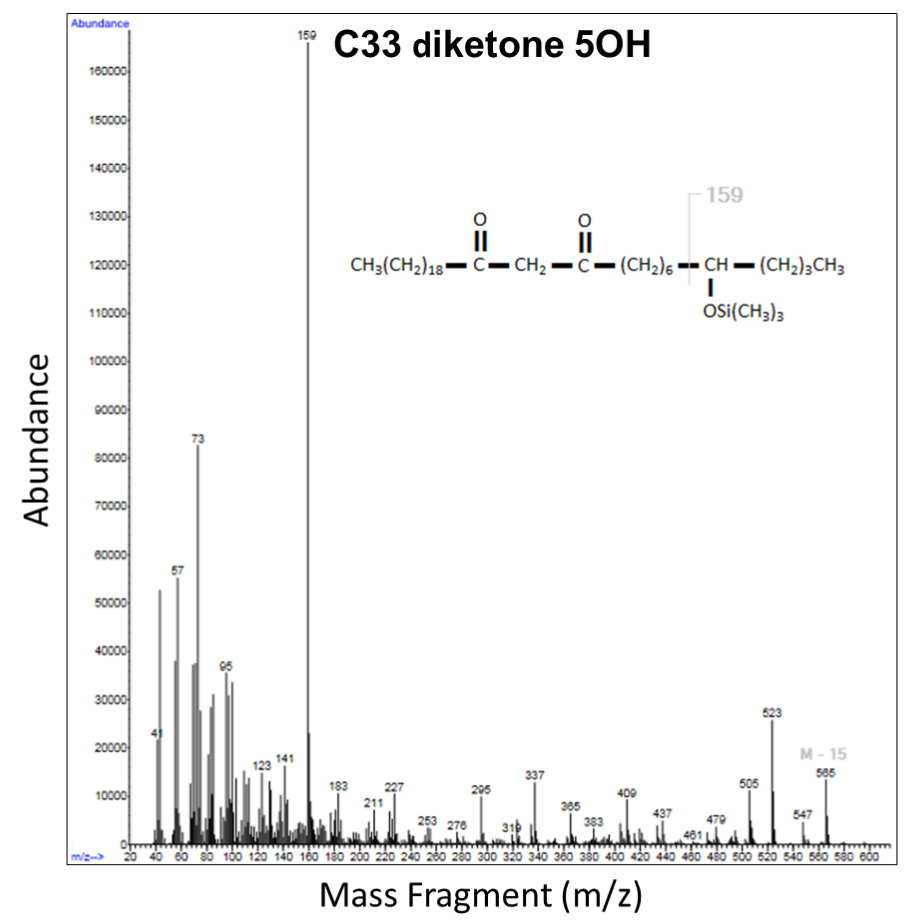

Supplemental Figure 3 